Retrospective Case Series

\title{
Treatment Outcomes after Combination Interventional and Cognitive Motivational Counseling on Analgesic Medication Use in Patients with Chronic Spine Pain
}

John Jerome, $\mathrm{PhD}^{1}$, Ryan Topham, MD¹, Anna Dematatis, $\mathrm{PhD}^{2}$, and Josh Corteville, $\mathrm{BS}^{3}$

\begin{abstract}
From: ${ }^{2}$ Compass Health, Compass Rehabilitation Center, East Lansing, MI; ${ }^{2}$ Battle Creek VA Medical Center, Battle Creek, $\mathrm{Ml}$; ${ }^{3}$ Wayne State University Medical School, Detroit, MI.

Dr. Jerome and Dr. Topham are with Dept. of IPM, Compass

Health, Compass Rehabilitation

Center, East Lansing, MI.

Dr. Dematatis is Clinical

Psychologist/Contractor with Battle Creek VA Medical Center, Battle Creek, MI.

Address Correspondence: John Jerome, PhD Compass Health

Compass Rehabilitation Center 205 E Saginaw

East Lansing, MI 48804

E-mail:

jjermoe505@aol.com

Disclaimer: There was no external funding in the preparation of this manuscript. Conflict of interest: Each author

certifies that he or she, or a member of his or her immediate

family, has no commercial association (i.e., consultancies, stock ownership, equity interest, patent/licensing arrangements, etc.) that might pose a conflict of interest in connection with the submitted manuscript.
\end{abstract}

Manuscript received: 09-03-2014 Revised manuscript received: 11-30-2014

Accepted for publication: 01-09-2015

Free full manuscript: www.painphysicianjournal.com
Background: Pain interventionists can interrupt pain through anesthetic blockade of neural transmission to virtually any part of the body. Temporary pain relief can be achieved by the direct application of targeted anesthetic. Diagnostically, nerve blocks help identify specific pain generators, refine differential diagnosis, and disrupt the neural transmission mechanisms to stop pain generation peripherally.

Objective: This study of patients with chronic spine pain was conducted to test the hypothesis that decreasing pain through interventional techniques coupled with cognitive motivational counseling can be highly effective in reducing chronic pain interference, reliance on prescription opioids, and enhancing overall function and quality of life.

Study Design: Retrospective case series.

Setting: Rehabilitation center.

Methods: Patients: This study involved a retrospective cohort of 78 consecutive patients with spine pain that underwent interventional procedures and cognitive motivational counseling, as well as a comparison group of 77 consecutive patients that underwent interventional procedures only. Outcome Measures: Pain intensity (DoD VAS), Functional capacity (DoD SS), Global Appraisal (PGIC), Pain site measurement (Drawing), and prescription medication use questionnaires were administered at initial evaluation and after treatment. Pre- and post-treatment changes were compared using paired t-tests. Chi-squared analysis was performed pre- and post-treatment for medication use.

Results: The pre- and post-treatment scores for pain intensity, function, and global appraisal demonstrated significant response to treatment $(P<0.001)$ for the combined interventional and cognitive motivational group $(P<0.001)$ and the interventional only group $(P<0.05)$. Compared to initial intake, opioid $(P<0.01)$, benzodiazepine $(P<0.01)$, muscle relaxant $(P<0.05)$, and antidepressant/antianxiolytic $(P<0.05)$ use only decreased for the combined interventional and cognitive motivational group.

Limitations: This is a retrospective study using medical records and patient self-reported symptoms with possible missed coding and no true random selection, assignment, or genuine control group comparison.

Conclusion: This study's results support the hypothesis that a combined interventional and cognitive motivational counseling treatment program can be effective in decreasing spine pain, reducing prescription pain medication use, and improving overall quality of life in chronic spine pain patients.

Key words: Spine pain, interventional pain procedures, cognitive motivational counseling, analgesic medication

Pain Physician 2015; 18:287-297 
P ain is the most common reason patients seek physician care. An estimated $30 \%$ of US adults are currently in chronic pain that has lasted 6 months or more, with back pain being the most prevalent (1). In the US, $\$ 500$ to 650 billion dollars is spent annually on health care expenses (2), with increased prescribing of opioids for chronic pain. In fact, Americans who make up $4 \%$ of the world population consume $80 \%$ of the world's supply of pain medication. Prescription opioid analgesics are the most commonly abused drug in the US (3), killing 14,800 people a year, which is more than heroin and cocaine combined (4).

Pain interventionists can interrupt pain through anesthetic blockade of neural transmission to virtually any part of the body. Temporary pain relief can be achieved by the direct application of targeted anesthetic. Diagnostically, nerve blocks help identify specific pain generators, refine differential diagnosis, and disrupt the neural transmission mechanisms to stop pain generation peripherally. Interestingly, the pain relieving effects of local anesthetics can often exceed the duration of chemical blockade of neural transmission. Blocking persistent pain may help prevent some cases of central sensitization (5), and the disabling nature of chronic pain from cognitive and affective factors. Psychologically the extended pain relief from anesthetic blockade may also result from the creation of pain-free intervals during which the patient can experience enough relief to learn new pain behaviors, thinking patterns, and more adaptive pain coping strategies (6-9).

Chronic spine pain (10) patients commonly have pain and fear of movement (11-16), called kinesiophobia (16). They are distressed and believe physical activity is harmful to their back health. Their perception is that the pain cannot be controlled, which leads to physical inactivity, fear of movement, avoidance strategies (1720), and reluctance about stopping their prescription opioids. In reality, increasing physical movement significantly enhances physical and psychological health (15). Blocking the pain signal allows a time of pain-free motion, an opportunity to reduce opioids, a time of clarity of thought, and an opportunity to change these long-standing learned pain behaviors.

Patients often require a cognitive behavioral (21-24) and motivational (25-28) approach to become comfortable physically moving again and to reduce their reliance on opioids for chronic pain management $(5,29,30)$. Combining interventional blockade while encouraging prescription opioid withdrawal, exercise, and pain self-management is the interdisciplinary treatment model proposed. Our hypothesis is that blocking the pain signal would set the stage for reducing opioid use and that employing cognitive motivational counseling strategies to encourage both physical movement and self-management of pain symptoms may be highly effective in reducing chronic pain behaviors, reliance on prescription opioids, and enhancing overall function and quality of life.

\section{Methods}

\section{Pain Metrics}

Best practice models (31) recommend core pain metric domains often utilizing visual analog scales (VAS) focused on pain intensity, functional capacity, and pain interference on mood and quality of life. There is good evidence pain VAS scales have construct validity, test-retest reliability, and patient compliance (32). Five major pain domains adjusted for chronic back pain were used as the pain metrics in the study.

\section{Pain Intensity (DoD VAS) Scales}

A substantial upgrade to VAS scaling metrics occurred when the Department of Defense (DoD) recently upgraded and standardized their VAS scales (33) across all levels of their medical care and training for, "widespread use in the Department of Defense and Veterans Health Administration" (33). We used the upgraded Department of Defense Visual Analog Scale (DoD VAS) in this study for measuring pain intensity and also adapted their supplemental questions to measure the impact of pain on function.

\section{Functional Capacity (DoD SS) Supplemental Questions}

We chose to evaluate the bio-psychosocial domain (34) of pain by continuing with this DoD model of experiential and functional language anchored across an 11-point scale, and including their DoD SS scales which focused on pain interference with 1) general activity including social recreational and family activities, 2) mood, anxiety or depression associated with the pain 3) sleep, including falling asleep, staying asleep, or obtaining rest, 4) stress caused by the pain on relationships within the family and finances, 5) concentration ability to think, remember, and problem solve. A sixth question was added about the ability to work: 6) work, including both work outside the home and housework. We adjusted anchor words moving from the military 24 
hour timeline to a 30 day timeline to use this metric in our chronic spine pain population.

\section{Global Appraisal (PGIC) Scale}

A third domain, the Patient's Global Impressions of Change (PGIC) Scale measures an overall quality of life construct asking whether the patient perceives their life as satisfying and fulfilling or they find the chronic pain experience adverse and their quality of life being worse $(35,36)$.

The PGIC is a 7-point scale and was adjusted for consistency to the more familiar 11-point scale, with experiential and functional language to again allow chronic pain patients to more fully describe their global estimate of pain improvement, lack of change, or worsening of symptoms.

\section{Pain Site Measurement}

A fourth domain we employed was the pain drawing $(37,38)$ to calculate the number of pain sites reported pre and post. The human body was divided for our purposes into10 body regions, creating an 11-point scale. The patients colored in painful areas creating a score equal to the number of regions shaded.

\section{Prescription Medication Use}

The fifth domain measured a specific pain - behavior - the percentage of patients requesting and receiving prescribed opioids, benzodiazepines, muscle relaxants, antidepressants, and anxiolytics pre- and post-treatment. Chart audits and the Michigan Automated Prescription Service (MAPS) (39) were employed as necessary for verification of scheduled drug prescriptions written and filled.

\section{Design}

This case series included 160 consecutively treated adult chronic back pain patients collected as part of a retrospective clinical audit over a 6-month period across 2 interventional pain treatment outpatient medical sites. All were reporting pain significant enough to require referral to specialized interventional pain management by their primary care physicians. All had a diagnosis of chronic spine pain and were reporting significant pain interference in mood, function, and quality of life. Inclusion criteria included failing at both conservative strategies for pain relief and chronic opioid prescribing. The patients needed to be of sufficient health and medically stable for beginning exercise and anesthetic blockade. Medical examination including a bio-psychosocial review of history, recent imaging, rou- tine lab tests, and spinal examination was performed. The data for the study were collected as part of routine intake and discharge procedures in an anonymous database. Permission to access and integrate the database was given by the patients upon admission and administrative approval was obtained.

Exclusion criteria consisted of evidence of a psychiatric disorder (active psychosis, risk of suicide, or severe personality disorder) and interfering with interventional or cognitive behavioral motivational counseling. Patients with evidence of any malignancy, pending surgery, acute, or emerging physical health problems requiring medical or surgical care were also excluded.

\section{Patients}

Eighty consecutive patients served as the treatment group and 80 patients served as a comparison group. Of the 160 patients, 156 completed questionnaires at admission and post-treatment and their baseline characteristics are presented in Table 1. Prior to admission, all patients were receiving medical care from a primary care physician who followed recognized guidelines $(40,41)$ for conservative spine pain management $(5,30)$. Patients' current medical history, medication records, previous physical examination, imaging, lab work, and surgical and pain history were updated and individually analyzed. Average patient age was 56.8 years old with $57.7 \%$ women and $43.3 \%$ men. In addition, $54 \%$ reported this pain episode lasting 6 to 12 months, $26 \%$ reported pain duration of 2 years, and $20 \%$ reported chronic pain for over 3 years.

All patients reported having chronic pain on admission severe enough to substantially interfere with mood, function, and quality of life. Seventy-four percent were taking opioids, 34\% were taking benzodiazepines, $21 \%$ were taking muscle relaxants, and $30 \%$ were using antidepressants or anxiolytics. Despite pharmacologic intervention, patients did not report pain or symptom control. Average pain intensity score was 6.4 on a 0 to 10 scale.

\section{Interventional and Cognitive Motivational Counseling Treatment Group}

This group consisted of 78 consecutively treated chronic spine pain patients. With acceptance criteria met, the interventional physician then orchestrated an individualized interventional, physical therapy, and cognitive motivational counseling program $(40,41)$ focused on decreasing prescription medication use and increasing physical activity $(5,30)$. 
Cognitive motivational counseling consisted of open-ended questions (25) about their fear of movement and ambivalence about giving up opioids. Reflective listening and brief empathic responding focused on the patients' fear and anxiety about change. Attention narrowed in on the discrepancy between the patients' persistent medication use, lack of physical activity, and reported goals of improved function and quality of life. The staff avoided arguments and direct confrontation about the discrepancy between stated goals and behavior, which was seen as counterproductive. Fears and anxieties causing resistance to physical activity or decreasing medication was directly addressed in a collaborative manner. The patient was viewed as a highly respected and valuable resource in generating novel solutions and new perspectives. The patients realized quickly that they were responsible for choosing and acting on their personal change plan. The treatment package was based on 1) blocking the pain signal, 2) re- storing function to the musculoskeletal system through exercise/physical therapy, and 3) cognitive behavioral modification focused on helping the patient not rely so heavily on prescription medications and psychologically encouraging self-management for their own chronic pain following treatment. Patients in this active treatment arm were treated over the 6-month measurement period averaging 4.1 interventional procedures, 6.6 face-to-face physician sessions, 10 physical therapy visits, and one individual 50 minute session with a pain psychologist to discuss ambivalence regarding medication use and activity levels (Table 1).

\section{Comparison Group}

Because this was field research and a practice based clinical study of consecutive patients over 6 months, there was no opportunity to withhold treatment or randomly select or assign to a waiting list or no treatment control group. A hospital-based outpatient inter-

Table 1. Characteristics of patient's with chronic spine pain in the Treatment group and Comparison group, admitted and treated from January to June, 2013. $(n=160)$

\begin{tabular}{|c|c|c|}
\hline & Treatment Group & Comparison Group \\
\hline Variables & $\begin{array}{c}\text { Intervention and Cognitive } \\
\text { Motivational counseling }(n=80)\end{array}$ & Intervention only $(\mathrm{N}=\mathbf{8 0})$ \\
\hline Age (Years) & 55 & 58.7 \\
\hline \multicolumn{3}{|l|}{ Sex } \\
\hline Female (\%) & $62.5 \%$ & $52.9 \%$ \\
\hline Male (\%) & $37.5 \%$ & $48.1 \%$ \\
\hline \multicolumn{3}{|l|}{ Pain Duration (This Episode) } \\
\hline 12 or less months (\%) & $62.5 \%$ & $45.2 \%$ \\
\hline 12 to 24 months (\%) & $18.8 \%$ & $14.6 \%$ \\
\hline 24 to 36 months (\%) & $7.5 \%$ & $15.1 \%$ \\
\hline 36 or more months (\%) & $11.3 \%$ & $25.1 \%$ \\
\hline \multicolumn{3}{|l|}{ Treatments (Average No) } \\
\hline Office Visits & 6.6 & 6.1 \\
\hline Interventions & 4.1 & 4.6 \\
\hline Acupuncture & 0.05 & 0 \\
\hline Massage & 0.02 & 0 \\
\hline Physical Therapy (Visits) & 7 & 0 \\
\hline Psychology Sessions & 1 & 0 \\
\hline \multicolumn{3}{|l|}{ Medication Classes } \\
\hline Opioids & $83 \%$ & $69 \%$ \\
\hline Benzodiazapines & $36 \%$ & $32 \%$ \\
\hline Muscle Relaxants & $19 \%$ & $22 \%$ \\
\hline Antidepressants/Anxiolytics & $22 \%$ & $37 \%$ \\
\hline
\end{tabular}


ventional only population of 80 consecutive patients served as the comparison group.

The comparison group all met the same inclusion and exclusion criteria and completed all the same pain metrics pre- and post-test as the treatment group. Follow-up meetings consisted of nurse practitioner coordinated medication reviews and refills and responding to follow-up prescription opioid requests. This group averaged 4.6 interventional procedures. Patients were seen for monthly prescription renewals and averaging 6.1 follow-up prescription request visits. No physical therapy or cognitive motivational intervention to encourage movement or reduce prescription opioid use was initiated.

\section{Statistical Analysis}

To accommodate our chronic spine pain population, measurements were slightly modified to consistently have all metrics employ 0 to 10 point scales and more precise anchor words. To assure the testing instruments were robust, separate reliability checks were performed on both the treatment and comparison group pain metrics pre- and post-treatment. All analyses were performed with SPSS 21.0 software (SPSS Inc., Chicago IL). Spearman's rho correlation coefficients (rho values) which are suitable for ordinal data and do not need to assume linearity and constant variance were used to measure the average of the split-half reliabilities computed for all possible halves for each measure to determine test-retest reliability and validity across all dependent variables at all measure points.

Internal consistency reliability coefficients were calculated across all pain metric domains for both treatment and comparison groups, at admission and 6 months post-testing. Spearman's rho split half reliabil- ity coefficients were significant at the $P=0.01$ (2-tailed) for the following pain metrics: pain intensity (rho = 0.740 to $.503 ; 158 \mathrm{df}$ ), sleep interference (rho $=0.602$ to $0.372 ; 157 \mathrm{df}$ ), general activity level (rho $=0.814$ to $0.447 ; 158 \mathrm{df}$ ), mood and ability to concentrate (rho = 0.849 to $0.438 ; 156 \mathrm{df}$ ), work-like activity (rho $=0.814$ to $0.416 ; 158 \mathrm{df}$ ), ability to handle stress (rho $=0.780$ to $0.475 ; 156 \mathrm{df}$ ), and global appraisal of functioning (rho $=0.622$ to $0.347 ; 158 \mathrm{df}$ ). These showed internal consistency and reliability coefficients pre- and posttreatment at the $P=0.01$ level (2-tailed). The split half reliability coefficients did not show significant correlations across possible halves for the number of pain sites (Spearman's rho $=0.402$ to $0.092 ; 154 \mathrm{df}$ ) and as a result pain sites was not included in the analysis.

\section{REsults}

\section{Interventional and Cognitive Motivational Counseling Treatment Group}

Change scores pre and post for pain intensity, function, and quality of life were then compared using paired t-tests. The difference in pain and function scores from admission to discharge showed a statistically significant favorable response for the interventional and cognitive motivational group pre-and post-treatment group $(P<0.001)$ across all measurement variables (Table 2).

There were clinically significant decreases in pain interference across all of the dependent variables following a cognitive motivational counseling focused on decreased prescription opioid analgesics. In this treatment group the pain intensity decreased $73 \%$. Sleep improved by $55 \%$, and $53 \%$ stated they were able to think, remember, and concentrate better, and were

Table 2. Pain, Function, and Global Appraisal change scores for the Treatment Group at Admission and Post Treatment.

\begin{tabular}{|c|c|c|c|c|c|c|c|}
\hline Variables & Admission & Mean (SD) & Post Treatment & Mean(SD) & $\mathbf{t}$ & df & $\begin{array}{c}\text { Significance } \\
\text { (2-Tailed) }\end{array}$ \\
\hline Pain Intensity & 6.44 & $(2.25)$ & 1.76 & $(2.14)$ & 16.077 & 77 & $<0.001$ \\
\hline \multicolumn{8}{|l|}{ Function } \\
\hline Sleep & 4.86 & $(3.25)$ & 2.17 & $(3.10)$ & 6.570 & 77 & $<0.001$ \\
\hline General Activity & 5.85 & $(2.85)$ & 2.46 & $(2.92)$ & 8.176 & 77 & $<0.001$ \\
\hline Mood & 5.18 & $(2.77)$ & 2.18 & $(2.57)$ & 7.351 & 77 & $<0.001$ \\
\hline Concentration & 3.58 & $(3.17)$ & 1.67 & $(2.42)$ & 3.795 & 77 & $<0.001$ \\
\hline Work & 6.13 & (3.06) & 2.85 & (3.01) & 6.886 & 77 & $<0.01$ \\
\hline Stress & 3.91 & $(3.21)$ & 2.25 & $(2.82)$ & 3.255 & 76 & $<0.001$ \\
\hline Global Appraisal & 8.28 & $(1.94)$ & 1.75 & $(2.50)$ & 16.688 & 77 & $<0.001$ \\
\hline
\end{tabular}


Pain Physician: May/June 2015; 18:287-297

Table 3. Frequency of medication use upon admission and discharge for both the Treatment and Comparison Groups*.

\begin{tabular}{|c|c|c|c|c|c|}
\hline Medication Classes & Admissi & $\mathrm{V}=\mathbf{8 0}$ ) & Post Treatment $(\mathrm{N}=78)$ & \multirow{2}{*}{\multicolumn{2}{|c|}{$\begin{array}{c}\text { Chi-Square }(\mathrm{df}=\mathbf{1}) \\
\text { P Value }\end{array}$}} \\
\hline Treatment Group & No. * & No & $\mathbf{X}^{2}$ & & \\
\hline Opioids & 67 & 12 & 57.386 & \multicolumn{2}{|c|}{$<0.01$} \\
\hline Benzodiazepines & 29 & 11 & 21.465 & \multicolumn{2}{|c|}{$<0.01$} \\
\hline Muscle Relaxants & 15 & 5 & 5.714 & \multicolumn{2}{|c|}{$<0.05$} \\
\hline Antidepressants and/or Anxiolytics & 18 & 8 & 4.592 & \multicolumn{2}{|c|}{$<0.05$} \\
\hline Comparison Group & No.* & No. & $\mathbf{X}^{2}$ & $P$ Value & $(P<.05)$ \\
\hline Opioids & 52 & 44 & 1.667 & 0.197 & NS \\
\hline Benzodiazepines & 25 & 22 & 0.476 & 0.490 & NS \\
\hline Muscle Relaxants & 17 & 16 & 0.656 & 0.417 & NS \\
\hline Antidepressants and/or Anxiolytics & 29 & 26 & 1.862 & 0.1724 & NS \\
\hline
\end{tabular}

* Sums do no equal $100 \%$ due to many patients taking multiple medications

better able to do work outside the home or routine housework. Stress levels in relationships and in the family decreased by $43 \%$ and the patient's global appraisal of quality of life at post-treatment was $79 \%$ higher.

Chi-square analysis of medication use was also performed pre- and post-treatment. There was a statistically significant decrease in prescription medication use for the treatment group. The amount of opioids decreased $88 \%$, benzodiazepines decreased $62 \%$, muscle relaxants decreased $65 \%$, and antidepressants/anxiolytics decreased $55 \%$ (Table 3 ).

\section{Comparison Group}

Change scores for the interventional only group on admission and post for pain intensity, function, and quality of life were also compared using paired t-tests. The differences in pain and function scores from admission to discharge showed clinically modest, but statistically significant (.05 level) improvement across the pain metrics (Table 4). Pain intensity decreased $18 \%$. Sleep improved by $22 \%$. General activity improved $18 \%$. The ability to think, remember, and concentrate was reported as $21 \%$ better, the capacity to do work outside the home or routine housework had improved $11 \%$. Stress level was improved by $31 \%$. Their overall global appraisal of quality of life at post-treatment was $20 \%$ better.

Opioid prescription use dropped $14 \%$. Antidepressants/anxiolytic decreased $8 \%$. Benzodiazepines decreased $15 \%$. Muscle relaxants decreased $16 \%$. Chisquare analysis of medication use at admission and post-treatment did not show statistically significant decreases and clinically there was no change in medication use or medication seeking behaviors at 6 months post-treatment.

\section{Discussion}

In this particular series of chronic spine pain patients, who had been refractory to conservative care, changes in pain metrics did not translate into decreased medication use. We found that without cognitive motivational counseling encouraging them otherwise, they continued to take pain medication at a similar pace to that measured at the start of their treatment. Simply stopping the pain signal did not stop medicationseeking behavior and patients in this series appeared to drift back to their pretreatment prescription pain medication use levels.

We know simply prescribing pain medicine rarely leads to lasting results (3). Pain-induced changes in thoughts, feelings, and behaviors must be addressed psychologically. Some people have to live with pain, and cognitive motivational counseling focused on reducing chronic opioid use is often necessary (42-44). Results of this study support the hypothesis that combining interventional blockade, physical movement, and active motivational counseling to reduce reliance on opioid medications is effective in decreasing pain intensity scores, improving function and quality of life, and perhaps most importantly, breaking the reliance on pain medication for symptom management.

Data from the comparison group found modest improvement in pain intensity, function, and quality of life, but not at a level that reached a $30 \%$ clinically relevant reduction in pain (66), and did not change patient medication-taking behaviors. An interventional outpatient treatment program can easily incorporate cognitive motivational counseling to have a therapeutic discussion about the cost, benefit, and risk of chronic opioid use, 
Combination Interventional and Motivational Counseling for Chronic Spine Pain

Table 4. Pain, Function, and Global Appraisal change scores for the Comparison group at admission and post treatment.

\begin{tabular}{|c|c|c|c|c|c|c|c|}
\hline Variables & \multicolumn{2}{|c|}{ Admission Mean (SD) } & $\begin{array}{c}\text { Post Treatment } \\
\text { Mean(SD) }\end{array}$ & $\mathbf{t}$ & \multicolumn{2}{|c|}{ df } & $\begin{array}{c}\text { Significance } \\
\text { (2-Tailed) }\end{array}$ \\
\hline \multicolumn{8}{|l|}{ Pain } \\
\hline Pain Intensity & 6.35 & $(2.21)$ & 4.57 & $(5.66)$ & 11.817 & 80 & $<0.05$ \\
\hline \multicolumn{8}{|l|}{ Function } \\
\hline Sleep & 6.04 & $(3.80)$ & 3.87 & $(3.80)$ & 7.478 & 77 & $<0.05$ \\
\hline General Activity & 6.40 & $(3.12)$ & 4.57 & $(2.97)$ & 6.899 & 79 & $<0.05$ \\
\hline Mood & 6.35 & $(3.81)$ & 4.11 & $(3.10)$ & 7.449 & 76 & $<0.05$ \\
\hline Concentration & 5.61 & $(5.13)$ & 3.54 & $(4.21)$ & 6.271 & 72 & $<0.05$ \\
\hline Work & 7.08 & $(4.10)$ & 5.98 & $(5.08)$ & 2.899 & 73 & NS \\
\hline Stress & 6.00 & $(5.19)$ & 3.95 & $(4.16)$ & 7.704 & 76 & $<0.05$ \\
\hline Global Appraisal & 7.39 & $(6.13)$ & 5.95 & $(4.98)$ & 5.892 & 72 & $<0.05$ \\
\hline
\end{tabular}

and can provide the opportunity to change thinking and pain medication-seeking and use patterns (45-48).

The pain metrics (Appendix 1) showed significant robustness, test-retest reliability, and reflected change scores that were consistent across pain, function, and quality of life measures. It is self-explanatory, easy to fill out, readily accepted by the patients, and consistent with clinical improvement.

This study has several weaknesses. This is a retrospective study using medical records and patient selfreported symptoms with possible missed coding. Data came from real clinical practice without true random selection, assignment, or genuine control group comparison. There already exists ample evidence to support the efficacy of interventional pain management and cognitive motivational counseling. The goal of this study was field testing to verify if these randomized controlled studies (RCTs) truly work in clinical practice and to provide clinical evidence of real world effectiveness.

Another weakness is that patients were specifi- cally referred, self-selected, and had ample insurance, up-to-date medical histories, and had their primary physicians' support. This study also cannot tell whether the improvements in the interventional treatment and cognitive motivational counseling treatment were the result of the biological benefits of going off pain prescription medications or the treatment itself. Long-term outcome measures are needed to determine relapse rates or reintroduction of opioid medication use.

Monitoring benefits, risks, side effects, and surveillance of possible inappropriate medication use becomes a distracting, and frankly, discouraging part of chronic spine pain management. Opioid tolerance and addiction are common and opiate-induced hypersensitivity is often the rule rather than exception with chronic spine pain patients. The benefit of any approach that decreases opioid prescription use and its recognized health risks and improves outcomes in terms of pain intensity, function, and quality of life warrants further study. 
Appendix 1. Michigan Pain Measurement Scale.

Michigan Pain Measurement Scales (MPMS)
Date:
Phone number you can be reached at:
Chief Complaint (Presenting Problem):

1.) PAIN SITES-On the diagram, shade in all the painful areas. Then, put an $\mathrm{X}$ at the area that hurts the most.

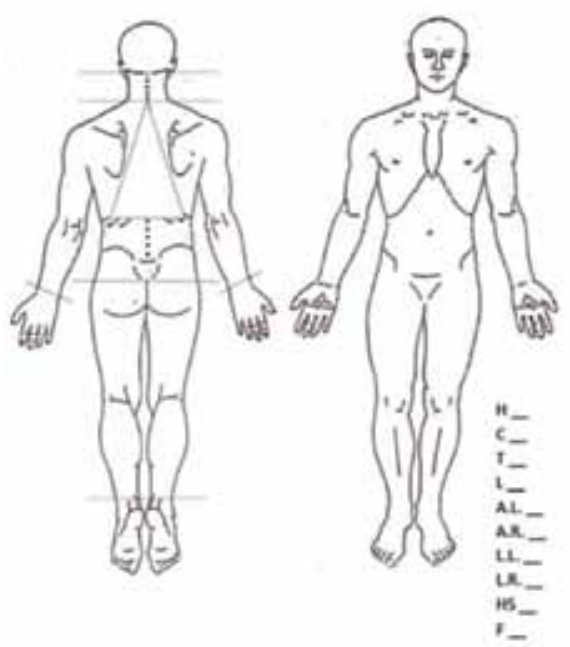

2.) MEDICATIONS - How many of these medications are you taking in a day?

Number

Anti-inflammatories

Narcotic Pain Relievers

Muscle Relaxers

Anxiety Medications

Depression Medieations

Sleep Medications

3.) INTENSITY- What is your pain level? - Circle the number that most acurately describes the level of your pain in the last 24 bours.

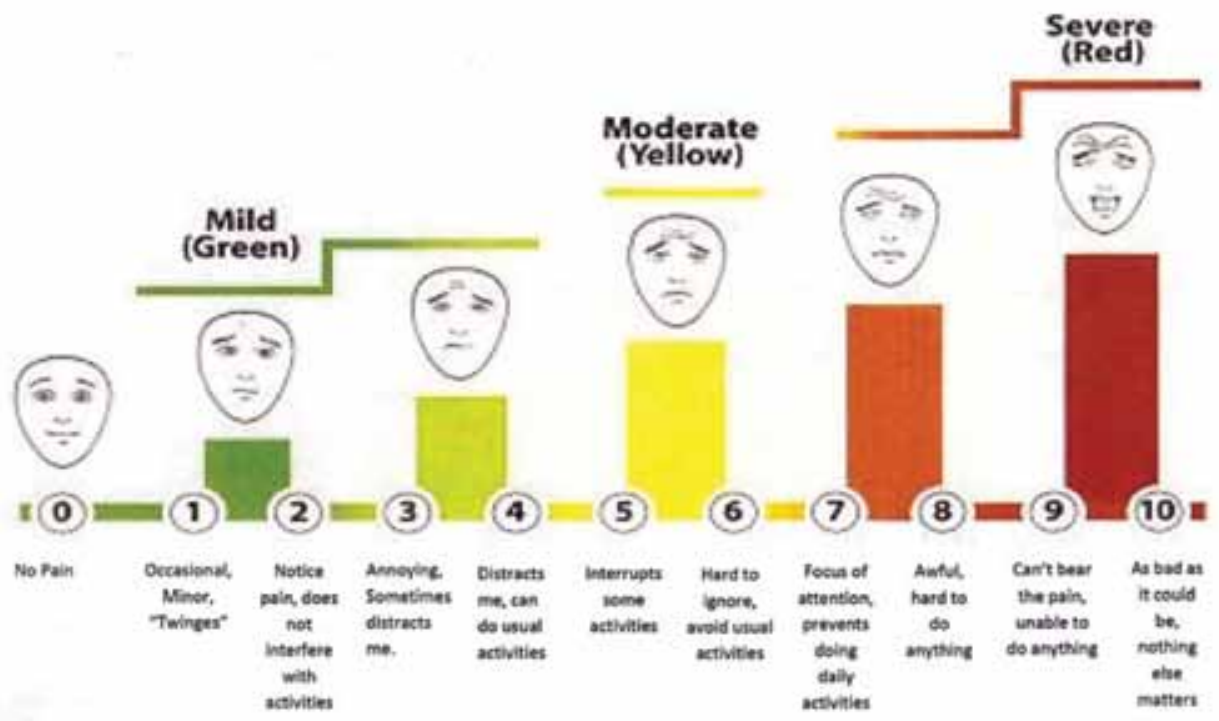


4.) FUNCTIONAL CAPACITY - How does your pain disrupt your daily life? Think back over the past 30 days and select the number that most describes how your pain is affecting you in each of the following categories

Sleep (To fall sleep, stay asleep, and obtain rest)

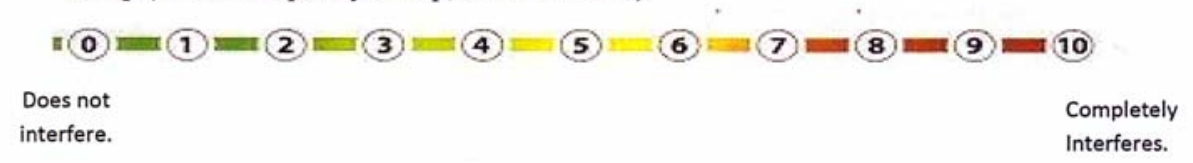

General Activity (Ability to do social, recreational, or family activities.)

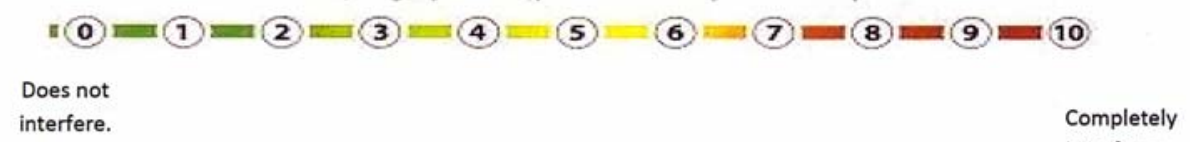

Mood - (Feeling distressed, anxious, or depressed)

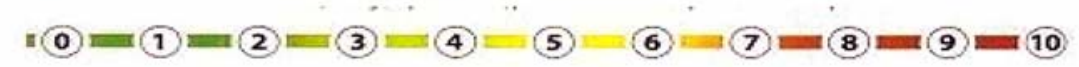

Work (Includes both work outside the home and housework.)

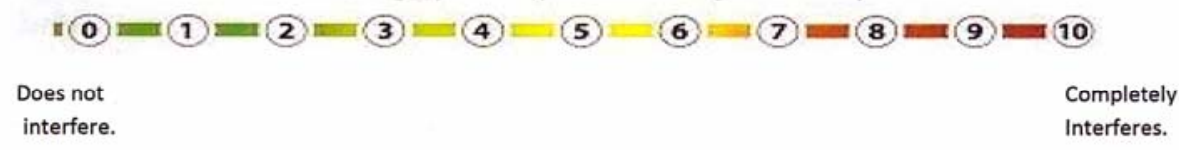

Stress Level (Relationships, family, financial.)

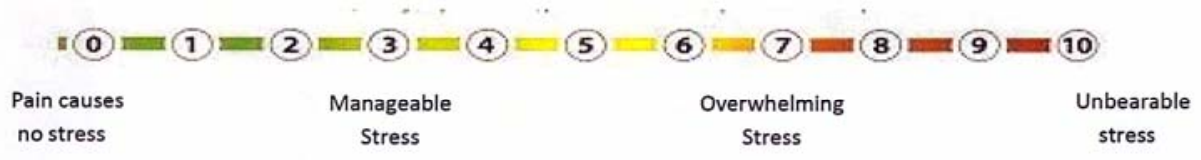

5.) Global Appraisal - Rate your overall quality of life today.

$\begin{array}{cccccc}\text { A little } & \text { The Same } & \text { A Little } & \text { A Great Deal } \\ \begin{array}{c}\text { A Great Deal } \\ \text { Better }\end{array} & \text { Better } & & \text { Worse } & \text { Worse }\end{array}$




\section{References}

1. Johannes CB, Le TK, Zhou X, Johnston JA, Dworkin RH. The prevalence of chronic pain in United States adults: Results of an Internet-based survey. J Pain 2010; 11:1230-1239.

2. Annual NIH Pain Consortium Symposia, Feb 15, 2013. Mechanisms, Models, Measurement and Management in Pain Research. www.mcbiNIH.Gov/ PubMed/11255208.

3. Alford DP, Livingston EH. Misuse of opioid medication. JAMA 2013; 309:2055.

4. National Institute of Drug Abuse. Analysis of opioid prescription practices. www.drugabuse.gov/news-events/ news-release/2011/04/analysis-opioidprescription-practices-finds-areas-concern

5. Elkiss ML, Jerome JA. Chronic pain management. In: Chila AG (ed). Foundations of Osteopathic Medicine. Lippincott Williams \& Wilkins, Baltimore, MD, 2011, pp. 253-273.

6. Willard FH, Jerome JA, Elkiss ML. Nociception and pain: The essence of pain lies mainly in the brain. In: Chila AG (ed). Foundations of Osteopathic Medicine. 3rd ed. Lippincott Williams \& Wilkins, Baltimore, MD, 2011, pp. 228-253.

7. Eccleston C, Williams AC, Morley S. Psychological therapies for the management of chronic pain (excluding headache) in adults. Cochrane Database Syst Rev 2012; 11: Do07407.

8. Scascighini L, Toma V, Dober-Spielmann S, Sprott H. Multidisciplinary treatment for chronic pain: A systematic review of interventions and outcomes. Rheumatology (Oxford) 2008; 47:670-678.

9. Practice Guidelines for Chronic Pain Management: A report by the American Society of Anesthesiologists Task Force on Pain Management, Chronic Pain Section. Anesthesiology 1997; 86:995-1004.

10. Merskey H, Bogduk N. Classification of Chronic Pain: Descriptions of Chronic Pain Syndromes and Definitions of Pain Terms. IASP Press, Seattle, WA, 1997.

11. Leeuw M, Goossens ME, Linton SJ, Crombez G. Boersma K, Vlaeyen JW. The fear-avoidance model of musculoskeletal pain: Current state of scientific evidence. J Behav Med 2007; 30:77-94.

12. Melzack R. Pain and stress: A new perspective. In: Turk DC (ed). Psychosocial Factors in Pain: Critical Perspective. The Guilford Press, New York, NY, 1999, pp. 89-106.

13. Turk DC. A duatheses-stress model of chronic pain and disability following traumatic injury. Pain Res Manag 2002; 7:9-19.

14. Vlaeyen JW, Linton SJ. Fear-avoidance and its consequences in chronic musculoskeletal pain: A state of the art. Pain 2000; 85:317-332.

15. Vlaeyen JWS, Kole-Snijders AMJ, Rotteveel AM, Ruesing R, Heuts PHTG. The role of fear of movement/(re)injury in pain disability. J Occup Rehabil 1995; 5:235-252.

16. van Wilgen $C P$, Dijkstra PU, Versteegen G), Fleuren MJ, Stewert R, van Wijhe $M$. Chronic pain and severe disuse syndrome: Long-term outcome of an inpatient multidisciplinary cognitive behavioural programme. J Rehabil Med 2009; 41:122-128.

17. Franses $M$, Woodard $M$, Norton R, Coggan C, Dawe M, Sheridan N. Risk factors associated with the transition from acute to chronic occupational back pain. Spine 2002; 27:92-98.

18. Fritz JM, George SZ. Identifying psychosocial variables in patients with acute work-related low back pain: The importance of fear-avoidance beliefs. Phys Ther 2002; 82:973-983.

19. de Jong JR, Vlàeyen JWS, Onghena P, Goossens MEJB, Geilen M, Mulder H. Fear of movement /(re)injury in chronic low back pain - Education or exposure in vivo as mediator to fear reduction? Clin J Pain 2005; 21:9-17.

20. Dionne CE. Psychological distress confirmed as predictor of longterm back related functional limitations in primary care settings. J Clin Epidemiol 2005; 58:714-718.

21. McCracken LM. Contextual CognitiveBehavioral Therapy for Chronic Pain. IASP Press, Seattle, WA, 2005.

22. Morley S, Eccleston C, Williams A. Systematic review and meta-analysis of randomized controlled trials of cognitive behaviour therapy and behaviour therapy for chroic pain in adults, excluding headache. Pain 1999; 80:1-13.

23. Morley S. Efficacy and effectiveness of cognitive behaviour therapy for chronic pain: Progress and some challenges. Pain 2011; 152:S99-S106.

24. Kerns Rd, Sellinger J, Goodin BR. Psychological treatment of chronic pain. Ann Rev Clin Psychol 2011; 7:411-434.

25. Miller WR, Rollnick S. Motivational Interviewing: Preparing People to Change. 2nd ed. Guilford Press, New York, 2002.
26. Smedslund G, Berg RC, Hammerstrom K.T, Steiro A, Leiknes KA, Dahl HM, Karlsen K. Motivational interviewing for substance abuse. Cochrane Database Syst Rev 2011; 5:CDoo8063.

27. Miller WR, Rollnick S. Motvational Interviewing. Guilford Press, New York, 2012.

28. Miller WR, Rose GS. Toward a theory of motivational interviewing. Am Psychol 2009; 64:527.

29. Dobscha SK, Corson K, Perrin NA,GC, Leibowitz RQ, Doak MN, Dickinson KC, Sullivan MD, Gerrity MS. Collaberative care for chronic pain in primary care: A cluster randomized trial. JAMA 2009; 301:1242-1252.

30. Kuchera ML, Jerome JA. Adults with chronic pain and depression. In: Chila AG (ed). Foundations of Osteopathic Medicine. $3^{\text {rd }}$ ed. Lippincott Williams \& Wilkins, Baltimore, MD, 2011, pp. 903-909.

31. Turk DC, Dworkin RH, Revicki D, G, Burke LB, Cella D, Cleeland CS, Cowan P, Parrar JT, Hertz S, Max MB, Rappaport BA. Identifying important outcome domains for chronic pain clinical trials: An IMMPACT survey of people with pain. Pain 2008; 137:276-285.

32. Litcher-Kelly L, Martino SA, Broderick JE, Stone AA. A systematic review of treatment outcomes in chronic pain clinical trials: IMMPACT recommendations. Pain 2008; 9:105-121.

33. Cucciare MA, Ketroser N, Wilbourne $P$, Midboe AM, Cronkite R, Berg-Smith SM, Chardos J. Teaching motivational interviewing to primary care staff in the Veterans Health Administration. J Gen Intern Med 2012; 27:953.

34. Linton SJ, Althoff B, Melin L, Lundin A, Bodin L, Magi A, Lidstrom K, Lighagen T. Psychological factors related to health, back pain, and dysfunction. Journal of Occupational Rehabilitation 1994; 4:1-9.

35. Guyatt GH, Freeney DH, Patrick DL. Measuring health-related quality of life. Annals of Internal Medicine 1993; 118:622-629.

36. Guy W. ECDEU Assessment Manual for Psychopharmacology (DHEW Publication No. ADM 76-338). Rockville, MD, US Department of Health, Education, and Welfare, Public Health Service, Alcohol, Drug Abuse, and Mental Health Administration, NIMH Psychopharmacology Research Branch, Division of Extramural Research Programs; 1976. 
37. Rollick S, Miller WR, Butler CC. Motivational Interviewing in Health Care: Helping Patients Change Behavior. The Guilford Press, New York, 2008.

38. Rosengren DB. Building Motivational Interviewing Skills: A Practitioner Workbook. Guilford Press, New York, 2008.

39. Michigan Automated Prescription Service. www.michigan.gov/mimapsinfo

40. Turk DC. Customizing treatment for chronic pain patients: Who, what, and why. Clinical Journal of Pain 1990; 6:225-270.

41. American Medical Association. Pain Management Series: www.amacmeonline.com/pain-mgmt. Accessed July 20, 2012.
42. Jensen MP, Romano JM, Turner JA, Good AB, Wald LH. Patient beliefs predict patient functioning: Further support for a cognitive-behavioral model of chronic pain. Pain 1996; 81:95-104.

43. Kerns RD, Rosenberg R. Predicting responses to self-management treatments for chronic pain: Application of the pain stages of change model. Pain 2000; 84:49-55.

44. Kerns RD, Rosenberg R, Jamison RN, Caudill MA, Haythornwaite J. Readiness to adopt a self-management approach to chronic pain: The Pain Stages of Change Questionnaire (PSOCQ). Pain 1997; 72:227-234.

45. Turk DC. Clinicians' attitudes about prolonged use of opioids and the issue of patient heterogeneity. Journal of Pain and Symptom Management 1996; 11:218-230.

46. Flor H, Fydrich TT, Turk DC. Efficacy of multidisciplinary pain treatment centers: A meta-analytic review. Pain 1992; 49:221-230.

47. McCracken LM, MacKichan F, Eccleston C. Contextual cognitive-behavioral therapy for severely disabled chronic pain suffers: Effectiveness and clinically significant change. Evr J Pain 2007; 11:314-322.

48. Rollnick S, Miller WR, Butler CC. Motivational Interviewing in Health Care: Helping Patients Change Behavior. Guilford Press, NY, 2007. 
